\title{
The Effectiveness of a Therapeutic Teaching Protocol in The Treatment of Reading Difficulties for Students of The Arabic- Speaking Primary
}

\author{
Ladjal Yassine
}

University Kasdi Merbah Ouargla, Algeria

\section{ARTICLE INFO}

Keywords:

Dyslexia

Phonemic awareness

Vocal working memory

Pedagogical treatment

program

\begin{abstract}
This study is concerned with highlighting the effect of vocal processing skills of vocal awareness and vocal working memory on the development of reading mechanisms and difficulties. The study was conducted on a total sample of 280 male and female pupils in the third, fourth and fifth phases of primary school ages 8-11, among them 50 children with dyslexia who were diagnosed according to a battery of standards that the researcher prepared for this purpose and that respond to the standards Psychometrics to build tests. The study aims to: To ensure the effectiveness of a pedagogical treatment program in developing reading skills for students with dyslexia dependent on phonological awareness activities and phonological working memory and the transition from part to whole gradually. In general, children with dyslexia suffer from a great and persistent difficulty in phonemic representation, in addition to a deficiency in the lower linguistic units in the Arabic language and their use to reach the skills of recognizing the written word by linking between the linear phonemic compatibility of the voice. Our findings support the evolutionary hypothesis of general disability in vocal processing skills and concluded that rhyme awareness appears before vocal syllabic awareness. A child at this level finds difficulty in phonograms with moving sound. Additionally, multiple regression analysis shows that poor vocal memory is the best indication of poor vocal awareness in the Arabic language. Studies also focused on the effectiveness of the proposed program for the treatment of vocal dyslexia in improving the ability to read in general.
\end{abstract}

\section{Introduction}

Reading is a mental activity in which many mental skills interfere, starting from the visual tracing of written symbols, then analyzing and treating them to get to know them to reach their meanings. Analytical or phonological pathway as shown in the two-way cascade model (DRC, Dual Route Cascade) by Coltheart and his colleagues (2001) as shown in the image below (figure 1) We have relied on this model as the background of the theory of dyslexia interpretation on the one hand and the preparation of a suitable program to improve reading for a group with dyslexia It remains difficult to determine tell her not to provide the main reason for their occurrence.

Dyslexia is a developmental disorder in learning to read. It is also a persistent weakness in the acquisition of the written language, and is characterized by great difficulties in the acquisition and automation of the mechanisms necessary to master the written word, despite

\footnotetext{
*Corresponding author E-mail address: ladjal.yacine@univ-ouargla.dz, ladjal.yassine@yahoo.fr 
the fact that the child is in school normally. Free from visual disturbances, they have normal intelligence and do not suffer from any mental retardation.

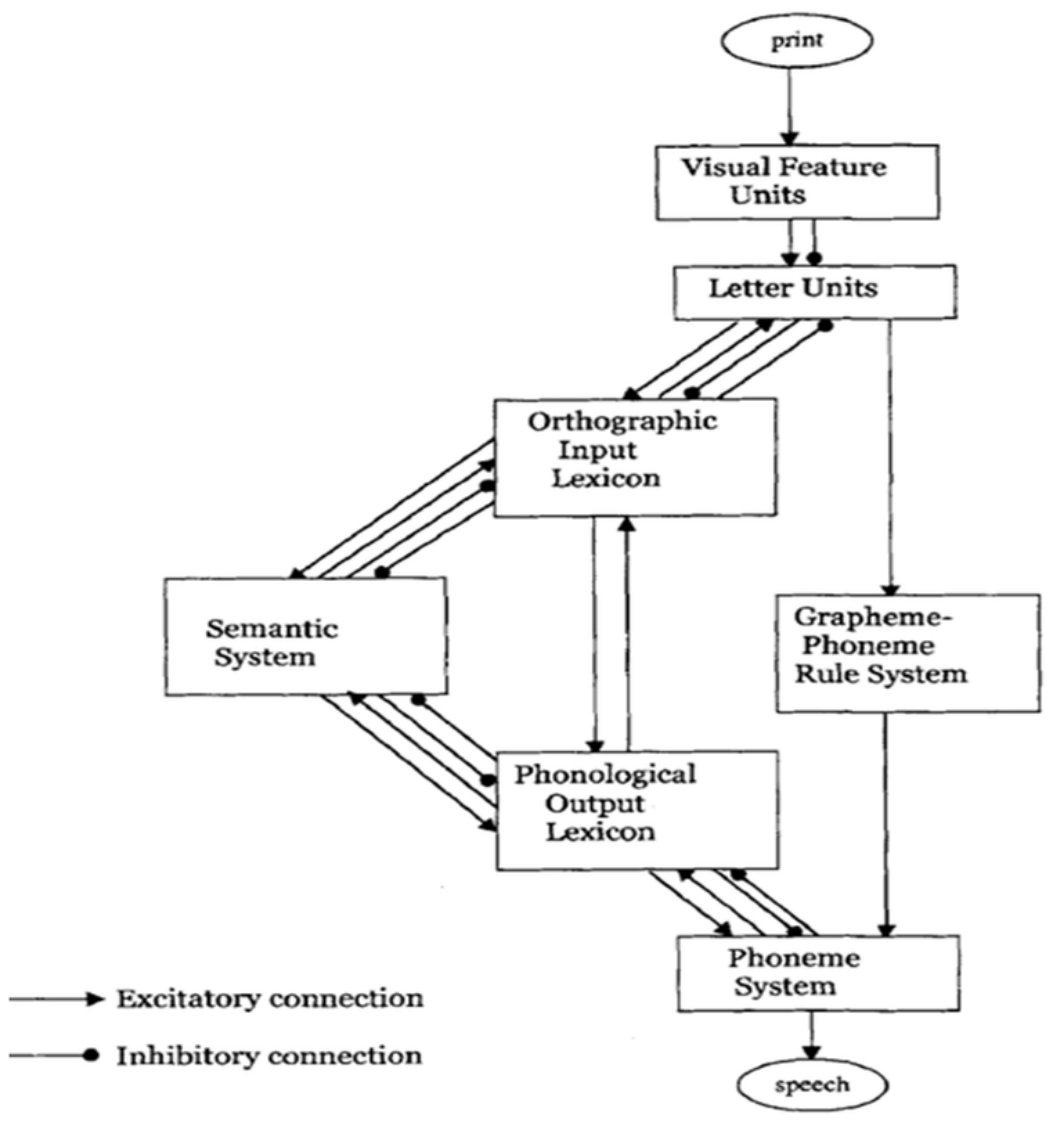

Figure 1. DRC (Dual Route Cascade) model from (Coltheart et al., 2001)

Learning to read in an alphabet like Arabic is a complex path that specifically requires the ability to manage the phonological components of a language. With regard to the basic stages of learning to read, it is distinguished by relating the harmonies between graphic and phonemic representations (graphemic-phonemic representations) which correspond to them (Frith, 1985). Consequently, the fixation of graphemes-phonemes harmonics requires the establishment of links between the written language and the oral language, which requires a child in particular the ability to analyze the written language as is the case with the language oral. The learner reader should be aware that words are divided into non-functional phonological units which are related to each other (phonemes), which represent phonological awareness. Phonological awareness makes it possible to perceive, cut out and manipulate the sound units of language such as the syllable, rhyme and phoneme. The Arabic language also has phonetic, grammatical, morphological and semantic characteristics which differ in terms of pronunciation and writing from other Indo-European languages, and this linguistic specificity appears in the number of its letters to 28 letters. regarding vocal sounds or vowels, there is "[? alfatha] [a], [? alkasra] [i], [? aldhama] [u], [? alsukun], [? achạdạ], attenuation ${ }^{1}$ [?atanwīn]"1

\footnotetext{
${ }^{1}$ [? atanwīn]: It is an audio writing of the word "Tanween", which in Arabic means the movements appearing above or below the letters and whose component is expressed by vowels so that they are syndicous to the consonants while they are pronounced, and they are considered as phonemes, with regard to writing, they are
} 


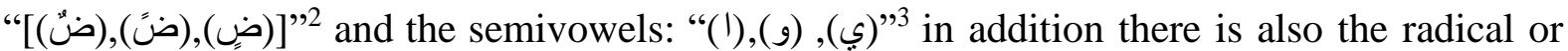
the verbal it has the same root of the verb or triple word, phonetic writing of the following sentence: the author wrote books [kataba ?alkātibu kitābun] or arabic writing "كَتَبَ، الكَاتِبْب، ${ }^{\prime}$ problem for the beginner child in its representation and evocation when the reading is needed here and several others syntax-grammatical derivative forms which represent graphophonemic changes very close together, which makes the situation of phonemic representation, highly difficult for children who are new to reading. So, the Arabic language is a syllabic language and not phonemic because consonants are linked to vowels. According to Cohen (1990) syllables can only have the forms, "cv, cvv, cvc"5 and in some cases "cvvc" (Cohen, 1990; Baccouche, 2003; Abu-Rabia, 1996). Treiman (1983) has shown in young children and ability to analysis of monosyllabic words in rhyme attack, by contrast they are unable to decompose into two phonemes an attack of consonant /consonant form or a rhyme of vowel / consonant form (Treiman, 1983). Rehabilitation, speech therapy for dyslexic children has two main objectives: to develop the skills required to learn to read and to develop skills that can be used as compensatory strategies. Phonological awareness skills and rapid naming affect the rapid acquisition of initial reading skills. (Wagner and Coll, 1997). Since the last twenties, research has multiplied over the knowledge processes involved in the difficulties which was represented in the study's reading dyslexia developmental or the evolutionary reading dyslexia. (Daneman et Carpenter, 1980; De Jong, 1998; Nation, Adams, bower-crane et monk, 1994; Seigneurie, Ehrlich, Oakhill et Yuill, 2000; Siegel et Ryan, 1989; Swanson, 1999, 2000; Swanson et Howell, 2001). These studies and research allow to indicate the existence of consensus and consensus in dealing with the difficulties of learning to read (dyslexia), which is represented by a deficiency in some cognitive processes (specific to the phonological awareness deficit and the deficit in storing and processing information in the working memory). Nevertheless, most studies are concerned with studying one of these paths, although the question remains in its entirety to know whether the difficulties in learning to read are due to a phonological

written to teach reading to beginners or in the Qur'an and are left to professional readers Like daily newspapers, which is a problem during reading for new learners.

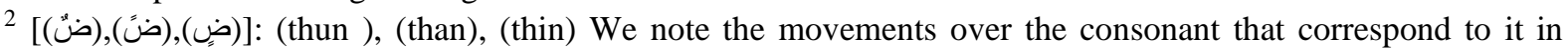
English with a distinctive specificity in the syllable properties (because there is always a mix between the consonant and the vowel in the Arabic language that distinguishes it in terms of writing and pronunciation its sounds).

3 ،“(ا), (و), and which are in the Arabic language, letters called semi-vowels, and they are corresponding in English (A), (W), (Y).

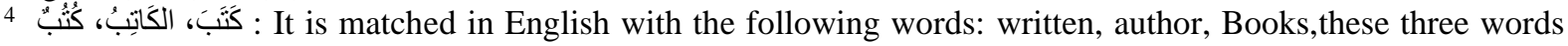
are written from the same root of the verb books. We note that the words in the Arabic language are derived from the root but maintain their shape and differ slightly between them and distinguish between them in the meaning, this feature in the Arabic language, whether it comes to writing or Pronunciation is a barrier for newborns to learn to read and write, as opposed to what it is in other languages such as English, French and other languages.

5 cv, cvv, cvc: They are, respectively, consonant + vowel $(\hat{\rho}=\mathrm{M})$, consonant + vowel + vowel, consonant + vowel + consonant (example: $\stackrel{\text { b }}{=}=$ cat), They are, respectively, consonant + vowel $(\mathrm{M})$, consonant + vowel + vowel, consonant + vowel + consonant (example: cat = cat), in Arabic language are syllables and there are open and closed syllables that can be called short and long syllables so short Consisting of a vowel and a consonant and long is composed of multiple letters. This gives specificity to the Arabic language as a sectional language. For reference, in Arabic there are short and long vowels, known as tides.

${ }^{6} \mathrm{cvvc}$ : $\mathrm{t}$ is a syllable consisting of a consonant letter at the beginning and another at the end, and they have two vowels, to be aware, because in Arabic the words always begin with consonants and the vowel is combined with them or the syndrome of writing and writing. 
or memory deficit or both. In a study by Wolf and colleagues (2000), they demonstrated that naming speed deficits on the one hand and phonological processing on the other are two disorders of severe language impairment. the development of the path of assembly requires that the child reaches phonemic an awareness which includes letter-phoneme harmonics, then collects sounds in syllables to obtain words before it reaches meaning, so that the concept of syllabic awareness or syllabics are acquired by children between 4 and 5 years of age, while phonemic awareness develops by learning to read (Wolf and Coll, 2000). Through the above, we wanted in our procedural study to answer the following main question: is the proposed educational program, activities effective in developing the ability to read in children with reading difficulties (in terms of accuracy or efficiency) or developmental dyslexia? As a sub-question, we say whether improving the skills of phonological awareness and phonological memory contributes to improving the reading performance of a group of children with dyslexia in general?

\section{Methods}

We randomly chose three primary schools at the level of Algiers, taking into account all the pupils at the state level and even throughout the Algerian territory; they adopt the same educational program in reading for the Ministry of National education, and the same hourly volume for the sessions. The study sample included a total of 280 pupils of both sexes (131 boys and 149 girls) from the third and fourth primary, who belong to three different schools. After having submitted all the 280 students selected for the experiment, we reached three groups (good student readers $\mathrm{NE}=93$, average readers $\mathrm{N}=137$, having "dyslexic" difficulties in reading $\mathrm{N}=50$ ) according to the academic level between $3^{\text {rd }}$ and $4^{\text {th }}$ year of primary school (CE).

We divided the sample of dyslexic students into two groups (a control group of 25 and an experimental group of 25 students) the measurement tools used include: - The Bells test, a cancellation task, allows a quantitative and qualitative assessment of visual neglect. And who is authorized to bringing visual research to the theme Strategy, light and detection is allowed light visual neglect, the purpose of which is to be used in our current study to isolate visual disturbances in our study sample (Gauthier and coll, 1989). in order to eliminate mental insufficiency in the population of our sample we have to use The test of the snowman is known under the name ${ }^{7}$ Goodenough Draw-A-Man test It is an intellectual development test, described and calibrated by Florence Goodenough (1926) considers that in the drawing of the man, "the intellectual element is the predominant factor in determining the result". It consists in asking a child to draw a man of free time without erasing it. The drawing is then noted taking into account the presence of a whole series of details. Due to its independence from socio-cultural factors and its great ease of use and rating, the snowman test is very widely used. It can give information on the intellectual development of the child, but also on his personality. In order to diagnose dyslexia at the study group and to select the study sample,

\footnotetext{
${ }^{7}$ Florence Goodenough granted mostly the importance to the presence in the drawing of different details and, to a lesser extent measure, proportions and motor coordination. In 1926, she created a system of quotation from the drawing of a snowman. From there, she asserted that components intellectuals existed in children's drawing. The study of drawing thus took on a new direction which was now theoretically linked to psychometric studies intelligence. With the publication of the Goodenough test, a new method evaluation of children's drawings was available. Using a scale dimension composed of 51 "absence-presence" binary criteria evaluating the quantity of details, proportions and motor coordination, Goodenough (1957) demonstrated that the design was cognitive rather than purely aesthetic. A review of Goodenough's "Bonhomme Test" has been undertaken by Harris in 1963. The latter refined the evaluation criteria by adding items to evaluate, going from 51 to 73 items, and making all the items more objective. Harris added a drawing of a female person with 71 items. The test has was standardized with a mean of 100 and a standard deviation of 15 .
} 
we applied the reading test and dyslexia evaluation, which is known as the "City Park ${ }^{8 "}$ (Ladjal, 2015), which is a text consisting of 219 unfamiliar words so that we can know the child's ability to spell and approach him For the method of compilation and evaluation of its ability to recognize written statements and link between phoneme and grapheme as in the test for assessing reading difficulties and dyslexia (Lefavrais, 2005), in addition to testing lists of words and quasi-words and words to determine the type of dyslexia taking into account the frequency of all (Word length) gradually passed a two-to-eight word, which is a differential diagnostic test, We also applied the phonological awareness test and aims to diagnose the child's skills in terms of the physical treatment of phonological units of the oral language, and it includes two parts of conscious phonological treatment and the first intended is rhyme awareness that contains rhyming recognition, rhyme production, rhyme symmetry. The second is phonemic syllable awareness and includes tasks: phonemic symmetry, deletion of the beginning, middle, and ending syllable and identification of the syllable (Ladjal, 2015; Ladjal, 2019). We also used the phonological working memory test is a test directed to children whose average age ranges between 8 to 12 years, and is applied to ordinary or sick children in order to assess their phonological circle by measuring the child's ability to save verbal and phonological information through the preservation capacity and includes the memory of numbers (the frequency of numbers item) From the right, the repetition of numbers from the left or in the opposite direction) word memory (the repetition of words from the right or directly) the repetition of words (from the left or in the opposite direction) syllable memory or likeness of words) Based on the completion of this test on the modified model (Baddeley AD, 2003; Baddeley, 2007 ) as well as the BELEC battery (Mousty \& Leybaert, 1999) and EVALEC battery (Sprenger-Charolles and coll, 2005), In the same context, we find the tool to detect dyslexia "Odedys" (Jacquier-Roux et al, 2005).

\section{Study Procedures}

The research plan includes two studies so that the second study is related to the results of the first. We are interested in this article to show the results of the second study, which is to measure the effectiveness of the proposed therapeutic program.

The first study identified a correlation between the items of phonological awareness (segmental and phonemic awareness, rhyme awareness) and phonological working memory with the ability to read from one side in the normal case and included 280 pupils and students from the third, fourth and fifth levels of primary school, in addition to studying the impact of each of Metaphysical skills on reading ability (effectiveness and accuracy of reading).

\footnotetext{
8 The approved reading test assesses the reading ability and its disorders of the primary school child. It consists of a text containing 219 words "decorated with drawings and with gradual printing of paragraphs of the text from the largest to the smallest size in order to verify that there is no problem at the level of vision and perception." The visual for written words ", the text is written on a sheet of A4 paper and in clear handwriting similar to the whole text, based on an application The child is asked to read the text aloud and what he can read from the text without errors, then the specialist or the examiner calculates the duration of the time it takes to read the text by the child using a "chronometer", with calculating the number of correct words read within 3 minutes, and the number of errors, If the child is unable to read the words of the text, he is asked to read the sounds of the letters and the syllables printed at the bottom of the paper, which are 26 sections (cv, cvc, cvv, $\mathrm{vcvcv}, \mathrm{cvvc}, \mathrm{vvc}$ ) and this is to encourage them to read the text later, and this consideration depends on the child's age. For reading entitled City Garden, it is a text taken from the writings of the writer and poet Victor Hugo (1873), corresponding to the goal to be measured and related to assessing the level of lexical or vocabulary decoding (mechanism and reading fluidity). The words of the text are difficult in terms of meaning and contain unfamiliar words, which makes The text is very specific and special and not like the texts that children usually encounter (Lefavrais, 1965; P., 1967; 2005). Therefore, the child cannot use inference strategies that can hide these difficulties in deciphering the text, just as Lefavrais in his edited edition in 2005.
} 
As for the second study, it is based on 50 male and female students with dyslexia who were selected from the above sample 280, and we divided 50 male and female students into two groups of 25 male and female students ( 25 for the control group) that are not subject to training in the proposed program, while the experimental group consisting of the same Issue 25 is subject to training in the program that we built and doing the pre- and post-test of the two groups to know the differences between the two measurements and determine the effect of improvement in relation to the experimental sample in the pre-measurement compared to the pre-measured and thus the effectiveness of the proposed program.

\section{Results and Analysis}

Table 1 shows us that all values of correlation coefficients for the functions of the phonological awareness test and the functions of the phonological working memory test are related to each other and statistically significant at the level of significance (0.01), so that the phonological awareness includes two underlying skills, which are phonemic segmental awareness and awareness Rhyme. Its relationship with phonemic working memory is very strong, which appears through their correlation coefficients respectively: phonemic crosssectional awareness of phonemic working memory is $\mathrm{p}=0.74$ and rhyme awareness of phonemic working memory was $\mathrm{p}=0.85$. With a preference for awareness of the rhyme as it relates to the phonological memory of work, which is the phonemic cross-sectional awareness. We also notice a preference for rhyme awareness as it relates to the phonological memory of work than is the phonemic cross-sectional awareness. We can say that they are two skills that interact and support together during phonological treatment of linguistic activities, and that rhyme awareness, especially the skill of identifying rhyming ( $\mathrm{p}=0.89$, .01 ), depends mainly on the phonological memory (phonological loop) and vice versa, that is, the phonological cycle develops And they are more effective and active when there are words that have the same rhyme.

Table 1.

The Correlation between the Items of Phonological Awareness and Phono Work Memory

\begin{tabular}{|c|c|c|c|c|c|c|c|c|c|}
\hline & $\begin{array}{l}\text { Reminder } \\
\text { Right words }\end{array}$ & $\begin{array}{l}\text { Reminder } \\
\text { Left words }\end{array}$ & $\begin{array}{l}\text { phrase } \\
\text { recall }\end{array}$ & $\begin{array}{l}\text { Recall of the } \\
\text { figures from } \\
\text { left to right }\end{array}$ & $\begin{array}{l}\text { Recall of the } \\
\text { figures from } \\
\text { right to left }\end{array}$ & $\begin{array}{l}\text { Recall of } \\
\text { phonemes }\end{array}$ & $\begin{array}{l}\text { Reminder } \\
\text { of syllables }\end{array}$ & $\begin{array}{l}\text { Recalling } \\
\text { images }\end{array}$ & $\begin{array}{c}\text { The phono } \\
\text { work } \\
\text { memory }\end{array}$ \\
\hline $\begin{array}{l}\text { Rhyme } \\
\text { identification }\end{array}$ & $.815^{* *}$ & $.790 * *$ & $.913 * *$ & $.878 * *$ & $.849^{* *}$ & $.800^{* *}$ & $.810^{* *}$ & $.546^{* *}$ & $.888 * *$ \\
\hline $\begin{array}{l}\text { Rhyme } \\
\text { production }\end{array}$ & $.584 * *$ & $.559 * *$ & $5.94 * *$ & $.601 * *$ & $.594 * *$ & $.581 * *$ & $.609 * *$ & $.448 * *$ & $.635 * *$ \\
\hline Rhyme pairings & $.653 * *$ & $.630 * *$ & $.675 * *$ & $.688 * *$ & $.659 * *$ & $.614 * *$ & $.646^{* *}$ & $.515^{* *}$ & $.705 * *$ \\
\hline $\begin{array}{l}\text { Total } \\
\text { conscience } \\
\text { rhymes }\end{array}$ & $.785 * *$ & $.757 * *$ & $.830 * *$ & $.82 * *$ & $.802 * *$ & $.763^{* *} *$ & $.792 * *$ & $.582 * *$ & $.852 * *$ \\
\hline $\begin{array}{l}\text { Phoneme } \\
\text { pairings }\end{array}$ & $.683 * *$ & $.673^{* *}$ & $.739 * *$ & $.749 * *$ & $.712 * *$ & $.680 * *$ & $.687 * *$ & $.567 * *$ & $.762 * *$ \\
\hline $\begin{array}{l}\text { First syllable } \\
\text { omission }\end{array}$ & $.598 * *$ & $.576^{* *}$ & $.665 * *$ & $.623 * *$ & $.609^{* *}$ & $.571^{* *}$ & $.567 * *$ & $.496 * *$ & $.653 * *$ \\
\hline $\begin{array}{l}\text { Omission of } \\
\text { midium syllable }\end{array}$ & $.538 * *$ & $.534 * *$ & $.600^{* *}$ & $.557 * *$ & $.550 * *$ & $.533 * *$ & $.503 * *$ & $.435^{* *}$ & $.590 * *$ \\
\hline $\begin{array}{l}\text { Last syllable } \\
\text { omission }\end{array}$ & $.632 * *$ & $.607 * *$ & $.700 * *$ & $.656^{* *}$ & $.657 * *$ & $.599 * *$ & $.621 * *$ & $.524 * *$ & $.693 * *$ \\
\hline $\begin{array}{l}\text { Phoneme } \\
\text { identification }\end{array}$ & $.605^{* *}$ & $.585^{* *}$ & $.679 * *$ & $.629 * *$ & $.612 * *$ & $.573^{* *}$ & $.565 * *$ & $.481 * *$ & $.657 * *$ \\
\hline $\begin{array}{l}\text { Phonemic } \\
\text { awareness }\end{array}$ & $.673 * *$ & $.656^{* *}$ & $.746^{* *}$ & $.709 * *$ & $.694 * *$ & $.653 * *$ & $.650 * *$ & $.552 * *$ & $.740 * *$ \\
\hline $\begin{array}{l}\text { Phonological } \\
\text { awareness }\end{array}$ & $.769 * *$ & $.746^{* *}$ & $.832 * *$ & $.810 * *$ & $.790 * *$ & $.747 * *$ & $.761 * *$ & $.599 * *$ & $.840 * *$ \\
\hline
\end{tabular}

Note: ** Strong correlation and statistically significant relationship at the significance level 0.01 . 
Table (2) shows that the correlation coefficient value between the total rate of phonological awareness tasks and the total rate of phonological work memory tasks is estimated at $\mathrm{P}=$ 0.84 , which is a very high and statistically positive value at the level of significance $(\mathrm{p}=$ 0.01 ), which indicates the presence of A strong positive correlation is statistically significant between phonological awareness skills and phonological work memory. - Table 2 shows us the correlation coefficient of the total rate of phonological awareness tasks and text reading represented in the accuracy of reading is $p=0.61$ statistically significant at the significance level of 0.01 and therefore there is a correlation between phonological awareness tasks with the accuracy of reading (the number of phonological errors during reading the text).

Table 2.

Correlation coefficients between phonological awareness tasks, phonological working memory, reading tasks and reading impairment

\begin{tabular}{|c|c|c|c|c|c|c|c|c|}
\hline & $\begin{array}{l}\text { Reading } \\
\text { accuracy }\end{array}$ & $\begin{array}{l}\text { Effective } \\
\text { Reading }\end{array}$ & $\begin{array}{c}\text { Reading } \\
\text { impotence }\end{array}$ & $\begin{array}{l}\text { Phonological } \\
\text { working } \\
\text { memory }\end{array}$ & $\begin{array}{c}\text { Rhyme } \\
\text { awareness } \\
\text { tasks }\end{array}$ & $\begin{array}{c}\text { Sectional } \\
\text { phonemic } \\
\text { awareness } \\
\text { tasks } \\
\end{array}$ & $\begin{array}{c}\text { Total } \\
\text { Phonological } \\
\text { awareness } \\
\text { tasks } \\
\end{array}$ & $\begin{array}{l}\text { Reading the } \\
\text { words, } \\
\text { quasi-words, } \\
\text { non-words }\end{array}$ \\
\hline Reading accuracy ${ }^{9}$ & 1 & & & & & & & \\
\hline Effective reading ${ }^{10}$ & $.869^{* *}$ & 1 & & & & & & \\
\hline reading disability & $-.698^{* *}$ & $-.728^{* *}$ & 1 & & & & & \\
\hline $\begin{array}{l}\text { Phonological working } \\
\text { memory }\end{array}$ & $.721^{* *}$ & $.786^{* *}$ & $-.716^{* *}$ & 1 & & & & \\
\hline Rhyme awareness tasks & $.635^{* *}$ &, $697^{* *}$ & $-.614^{* *}$ & $.851^{* *}$ & 1 & & & \\
\hline $\begin{array}{l}\text { Sectional phonemic } \\
\text { awareness tasks }\end{array}$ & $.523^{* *}$ & $.566^{* *}$ & $-.537^{* *}$ & $.740^{* *}$ & $.796^{* *}$ & 1 & & \\
\hline $\begin{array}{l}\text { Total phonological } \\
\text { awareness tasks }\end{array}$ & $.611^{* * *}$ & $.666^{* *}$ & $-.607^{* *}$ & $.839^{* *}$ & $.947^{* *}$ & $.948^{* *}$ & 1 & \\
\hline $\begin{array}{l}\text { Reading the words, quasi- } \\
\text { words, non-words }\end{array}$ & $.255^{* *}$ & $.237^{* *}$ & $-.203^{* *}$ & $.157^{* *}$ & $.248^{* *}$ & .041 & $.152^{*}$ & 1 \\
\hline
\end{tabular}

The phonemic cross sectional awareness, relationship (phonemic and segment awareness) with accurate reading appears in Table 2 with $(p=0.53, .01)$ and rhyme awareness $(p=0.63$, .01 ), which is a significant correlation relationship with little precedence in rhyme awareness from phonemic cross sectional awareness, That is, awareness of the rhyme contributes greatly to reading the text and that the skills of rhyme are easier for the Arab child than phonemic syllabic awareness, which is the first to appear and control. - The correlation coefficient between phonological awareness tasks with the effectiveness of reading ( $p=0.67)$, which is a statistical function at the level of significance .01, that the correlation coefficient between phonemic awareness of cross-sectional reading effectiveness $(p=0.57, .01)$. The value of the correlation coefficient between rhyme awareness of the effectiveness of reading $(p=0.70$, .01 ), which is a significant and powerful value compared to phonemic syllabic awareness, because the child's awareness of the rhyme increases the effectiveness of his reading (in terms of reading speed), and we also say that the text Containing words that have the same rhyme, reading is easier and faster.

\footnotetext{
${ }^{9}$ Reading accuracy: The accuracy of reading is the number of errors committed while reading the text.

${ }^{10}$ Effective reading: The effectiveness of reading expresses the speed of reading (that is, the number of words read in three minutes).
} 
With regard to the relationship of phonological awareness (phonemic syllabic awareness, rhyme awareness) with the total reading of words, quasi-words and non-words are estimated at $(\mathrm{p}=0.15)$, which is a statistically significant but very weak function.

Table 2 also shows us that there is a strong and negative relationship between reading disability and reading accuracy with the value of the correlation coefficient $(p=-.698)$ which is a statistical function at $(\mathrm{p}=0.01)$ and the same with regard to reading disability with the effectiveness of reading with a value of $(p=-.728)$ at the level of significance $(p=0.01)$ which is statistically indicative of a strong correlation Very negative and negative sign means that whenever reading skills are weakened, whether it comes to accuracy or effectiveness, it results in reading disability or dyslexia.
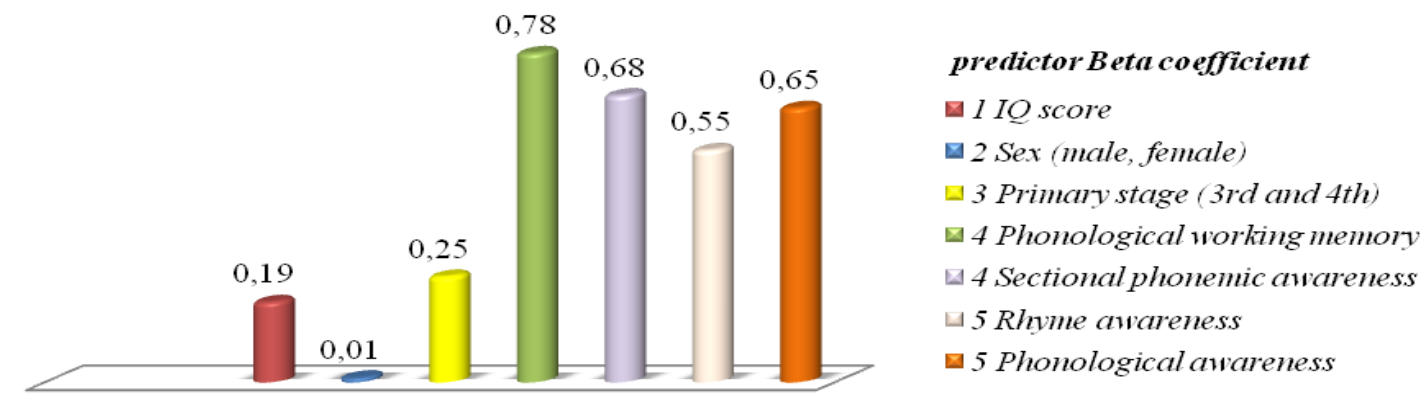

Figure 2. Gradient analysis of the gradient method for all functions of phonological awareness and phonological working memory on accuracy of reading, IQ, gender, study level

Looking at the value of the beta predictive coefficient (Figure 2.), we find that phonemic working memory comes first (1) with $\mathrm{p}=0.78$, and in second (2) phonological awareness comes in $\mathrm{p}=0.65$ with a precedence in that of phonemic segmental awareness with 0.68 and $p=0.55$ for consciousness In rhyme, in addition to $p=0.25$ for the academic level and $p=0.19$ for the intelligence factor in the third (3) and fourth (4) ranks respectively, they are weak values in terms of influencing the effectiveness of reading and in the rank (5) and last we find the sex factor by $\mathrm{p}=0.01$ which is a nonexistent value in this regression model. This confirms its findings that phonemic memory is the most important indicator in learning to read from phonological awareness. So that it appears in the latter that the phonemic syllabic awareness comes in the first stage (Level $3^{\text {rd }}$ and $4^{\text {th }}$ Primary) to learn to read and then the rhyme awareness at a later stage of learning .

On the other hand, the weakness of the memory of work and phonological awareness are considered indicators indicating the difficulty of reading in terms of accuracy and effectiveness, and taking a slight precedence of the phonological working memory over phonological awareness and this is due to the specificity of the Arabic language and the difficulty of representing its minor linguistic units (phonemes and syllables) because the voices and silos are combined together, so it is not possible to separate Silent on the voice (diacritics), for example, is a word taught. All words in the Arabic language are pronounced and read by diacritics (movements), which are deleted for the professional rider. This matter requires the intervention of phonological and visual work memory in order to link between it the sound and the form of boredom and assumptions.

\section{Results and Analysis of The Proposed Program}

Table (3) shows us the analysis of variance for the following tasks: reading tasks (reading effectiveness, reading accuracy, reading words, quasi-words, non-words), phonological awareness tasks, phonological memory work, reading impotence. This is to verify the existence of differences and differences between reading tasks, phonological working 
memory, phonological awareness, and reading deficits between the control and experimental group in the post measurement.

Table 3.

Analysis of mono-variability between the control and experimental group in reading tasks and reading deficits, phonological working memory and phonological awareness in telemetry

\begin{tabular}{|c|c|c|c|c|c|c|}
\hline Variables & $\begin{array}{c}\text { Source of } \\
\text { contrast }\end{array}$ & $\begin{array}{l}\text { Sum of } \\
\text { squares }\end{array}$ & $\begin{array}{c}\text { Degree of } \\
\text { freedom }\end{array}$ & $\begin{array}{l}\text { Average } \\
\text { scores }\end{array}$ & $\begin{array}{c}\text { The value } \\
\text { of "F" }\end{array}$ & $\begin{array}{c}\text { Significance level } \\
\mathrm{P} \text { value }\end{array}$ \\
\hline \multirow{3}{*}{ Reading accuracy } & Between groups & 6501.08 & 1 & 6501.08 & \multirow{3}{*}{264.06} & \multirow{3}{*}{.000} \\
\hline & Within groups & 1181.73 & 48 & & & \\
\hline & Total & 7682.81 & 49 & 24.62 & & \\
\hline \multirow{3}{*}{ Effective reading } & Between groups & 10961.87 & 1 & 10961,87 & \multirow{3}{*}{157.18} & \multirow{3}{*}{.000} \\
\hline & Within groups & 3347.64 & 48 & 6074 & & \\
\hline & Total & 14309.51 & 49 & 09.14 & & \\
\hline \multirow{3}{*}{ Read the words } & Between groups & 1.591 & 1 & 1.591 & \multirow{3}{*}{138.4} & \multirow{3}{*}{.000} \\
\hline & Within groups & .552 & 48 & 011 & & \\
\hline & Total & 2.143 & 49 & .011 & & \\
\hline \multirow{3}{*}{$\begin{array}{l}\text { Read likeness of } \\
\text { words }\end{array}$} & Between groups & 1.195 & 1 & 1.195 & \multirow{3}{*}{113.7} & \multirow{3}{*}{.000} \\
\hline & Within groups & .504 & 48 & 011 & & \\
\hline & Total & 1.699 & 49 & .011 & & \\
\hline \multirow{3}{*}{ Reading words } & Between groups & .966 & 1 & .966 & \multirow{3}{*}{80.6} & \multirow{3}{*}{.000} \\
\hline & Within groups & .576 & 48 & 012 & & \\
\hline & Total & 1.542 & 49 & .012 & & \\
\hline \multirow{3}{*}{$\begin{array}{l}\text { Reading } \\
\text { impotence }\end{array}$} & Between groups & 2178 & 1 & 2178.00 & \multirow{3}{*}{18.0} & \multirow{3}{*}{.000} \\
\hline & Within groups & 5811.52 & 48 & 12107 & & \\
\hline & Total & 7989.52 & 49 & 121.07 & & \\
\hline \multirow{3}{*}{$\begin{array}{l}\text { Phonological } \\
\text { working memory }\end{array}$} & Between groups & 0.76 & 1 & 0.76 & \multirow{3}{*}{60.7} & \multirow{3}{*}{.000} \\
\hline & Within groups & 0.60 & 48 & 001 & & \\
\hline & Total & 1.37 & 49 & & & \\
\hline \multirow{3}{*}{$\begin{array}{l}\text { Phonological } \\
\text { awareness }\end{array}$} & Between groups & 0.52 & 1 & 0.52 & \multirow{3}{*}{22.9} & \multirow{3}{*}{.000} \\
\hline & Within groups & 1.08 & 48 & רח & & \\
\hline & Total & 1.60 & 49 & 0.02 & & \\
\hline
\end{tabular}

The value of $F(48,1)=264.06$ at the level of significance $p=0.0001<0.05$ accordingly, it is a statistically significant value at the level of significance 0.05 , and it is also considered a large value that expresses the difference and the big difference between the experimental and controlling groups for the tasks of reading accuracy, as the scheme (2) shows us the difference and the important difference in the averages of the tasks of reading accuracy "AL Precision" among the control group and this experimental group, on the one hand, the difference and the difference between the averages, which appears in the average value of the squares between the groups, on the other hand, it shows us the effect of training in the proposed program to improve the reading ability in the difference between the averages of the two groups with regard to the accuracy of the reading. The same attachment with regard to the effectiveness of reading tasks, where the value of $F(48,1)=157.18$ at the level of significance $\mathrm{p}=0.000<0.05$ is a statistical function, and it is a large value that expresses the size of the difference between the averages of the two groups, and this important difference confirms both the mean of squares and the sum of squares Between the groups estimated at 10961.87 (see Table 3). Accordingly, there is a difference and a difference between the control and the experimental group with regard to the effectiveness of reading, due to the effect of training in the proposed program in favor of the experimental group. As shown in the scheme (3). As for word reading, the value of $F(48,1)=138.4$ at the level of significance $\mathrm{p}=0.000<0.05$ is statistically indicative of the presence of a difference and variance between the experimental and control groups, as the amount of the average squares and the sum of squares indicates the amplitude of the difference and that this difference Between the 
averages in favor of the experimental group (see scheme (2), and the reason for this large variation is due to the positive effect of the program proposed by the researcher.

In summary, we conclude from Table No. 3 that there are differences in the averages of the results of all metalinguistic skills (phonological awareness and phonological work memory) associated with reading in favor of the experimental group that was trained in the program that was prepared by the researcher in this study. Accordingly, the pedagogical training program based on phonological awareness activities and phonological work memory improves students' ability to learn good reading and reduces the number of errors committed in the text as well as increasing the speed of reading in children with dyslexia. Below we show the diagrams that represent the results of Table 3 to clarify the resulting differences for all studied variables that have a direct relationship to learning to read.

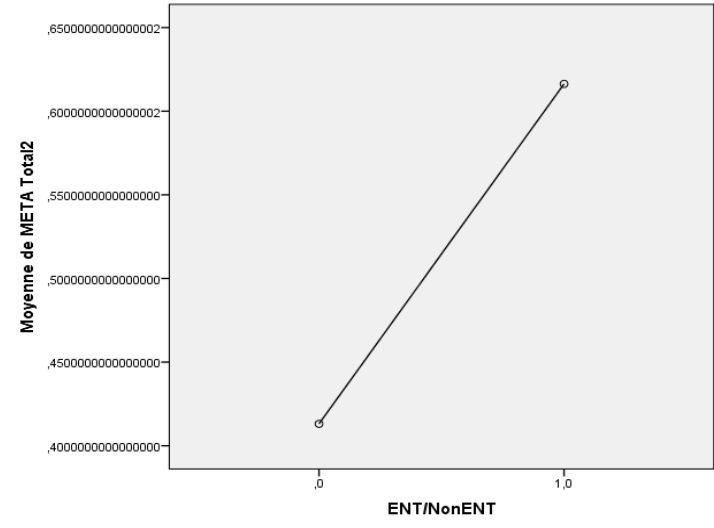

Scheme (1): Shows the difference between the averages for phonological awareness in the pre and post measurements between the group.

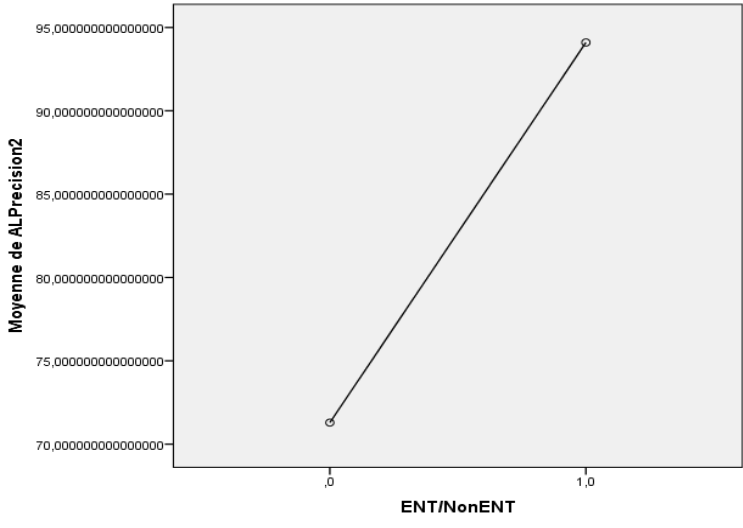

scheme (2): shows the difference in the results of the averages of reading accuracy in the pre and post test of the treatment program between the control and the experimental group.

schemes 1 and 2 clearly illustrate the positive differences in favor of the experimental group between pre and post measurement in terms of improving the effectiveness of reading, reading accuracy and phonological awareness skills. There are all other diagrams for each of the variables shown in Table 3 that I could not display for their large number, they represent the results of the table as will be mentioned Previously, and accordingly, the program that was prepared in this study is effective and effective in improving the ability to read as well as the linguistic cognitive skills associated with the latter for Arabic speakers.

\section{Discussions}

We come to discuss the results of our study the phonological working memory is closely related to the text-reading item (reading efficacy, reading accuracy) and little to the wordreading item and likeness of words and words. That is, reading quasi-words are more difficult than reading isolated words and reading words is more difficult than quasi-words, as the phonological work memory interferes greatly in the reading process, especially in encoding and processing verbal or phonological information for a short period of time in relation to this sensitive stage of learning to read any level $3^{\text {rd }}$ and $4^{\text {th }}$ primary, which are more present in children than phonological awareness, the results of our study are consistent with the study of Habib (2007), which showed that there is a strong relationship between the treatment of phonemic awareness, phonological working memory and reading skills (Habib et al, 2007). Wagner and his colleagues (1994) cause causality between phonological memory and learning to read, they exist at the level of a common skill for memory and phonological awareness, which is phonological coding or phonological representations (Wagner and Coll, 2006; Demont, Gombert,1996). The Hutton and Towse (2001) study also agree, in which 
they showed the correlation relationship with statistically significant between the functions of the phonological cycle and reading results in children between 8 and 11 years old (Hutton and Towse, 2001). The same results are in the study of Ellis and Large (1988) his studies confirm that there is no such thing as "reading", but rather different strategic mixes of information processing skills at different stages of development. He traced these stages of reading development and demonstrated that entering each new stage depends to some extent on the child's ability to the necessary skills in sub-components. This does not necessarily imply that it is the only the possible progression towards literacy-reading is a skill taught and therefore its growth must certainly reflect the style and content of the curriculum. Popular reading programs in English are generally similar after education in the first two or so years, progress is essentially self-determined, and the development progression described here can therefore be typical, in information processing terms it begins as an undifferentiated skill associated with knowledge of the letters of the alphabet, phonological awareness, and visual symbolic short-term memory processes. It then changes in character, being associated with holistic visual pattern recognition skills. By 6 years old phonological awareness and verbal short-term memory processes are by far the strongest associates. By 7 years old the better readers' skills are associated with analytic visual perceptual analysis, the learning of new symbol-sound associations, and sound blending skill. Reading has become a multifaceted ability tapping a wide range of different skills from language comprehension to analysis of the order of elements in a visual array (Ellis and Large 1988). The results of my current study showed analyzes of the differences between the one-way ANOVA averages shown in Table 3 and the presence of statistically significant differences between the pre-test and the experimental group between the experimental group and the control group in favor of the experimental group to measure the dimensions, although the results in the preliminary test were in favor of the group Control, so if that indicates, it indicates the effectiveness of our program in making a difference and improving their ability to read, which is directly related to an increase in the activation of vocal work memory and metaphysical skills, and all these results are confirmed by most studies On dyslexia programs that depend on the development of the above skills, we find, for example Mourad Ali Eissa (2014) study on dyslexia programs that depend on developing the above mentioned skills, confirm all these results, and he concluded in his study that the experimental group obtained the best results in acoustic, vocal, metaphysical sensitivity and proficiency tests as groups Subsequent tests were controlled, although there were no statistically significant differences between the two groups during the pre-test, due to the program that responded to the needs and interests of the experimental group. On the contrary, the control group was left to traditional teaching (Mourad, 2014). It goes in the direction of our approved point of view that indicates that the traditional methods used in our schools do not direct students as individuals to tasks and materials according to their cognitive abilities so that it is necessary to complete in the preschool stages i.e. before the age of seven in the syllabic or phonemic setting so that the child can perceive the phonological differences of words and their mental representations In the formation of words and then search for their meanings later, the stage of linking sound with sound included is necessary in the early stages of learning to read. the study of Alegria and Mousty (2004) demonstrated through their experimental works that activities designed to develop children's sensitivity to the phonological structure of speech are likely to help them learn to read. The effectiveness of these activities seems to increase if they are accompanied by the use of letters which allow the child to fix the referents of the phonological units which he manages to isolate mentally. In this context, it should be remembered that phonemic awareness does not seem to develop spontaneously. Methods specifically designed to help the child mentally isolate these units are therefore essential (Alegria and Mousty, 2004), the results of the study by Elbro and Scarborough (2004) this work shows that the predictive 
factors depend on the type of reading ability examined (recognition of written words, reading comprehension), the age at which the predictive factors are measured and the age at which reading skills are evaluated (Elbro and Scarborough, 2004). The researchers Ziegler and Goswami (2005) have indicated that the development of reading depends on phonemic awareness across all the languages studied so far. Languages differ in the consistency in which phonology is represented in spelling. And its results development differences in grain size of lexical representations and associated differences developmental reading strategies and the appearance of dyslexia by spelling. Differences in Lexical representations and reading across languages leave adults growing dictionary. Lexical organization and treatment strategies that are characterized by skilled reading in different spellings are affected by different growth restrictions in different writing systems (Ziegler and Goswami, 2005). who unanimously agreed on the effectiveness of their training programs to improve reading among dyslexic children, which relied on phonological awareness training between two experimental and control groups and that improvement in favor of the group The experimental trainer also found a trace of the Training to improve the reading level and the level of development of phonological awareness of their activities through the cutting and installation of clips and phonemes and composition of words, In addition to the Barbosa (2009) study, the differences in vocal working memory (phonological), phonological awareness, language skills (meanings of words, grammar, phonological characteristics) among Brazilian children with dyslexia and normal are identified (Barbosa and Coll, 2009). And the results indicated that there are deficiencies in these aspects among people with reading difficulties compared to the ordinary, and that early interventions improve them, which leads to improved reading skills.

\section{Conclusion}

We conclude, through the results of our current study, that there is a strong relationship between the skills of phonological awareness and the phonological work memory between them, as well as their strong association with the mechanism of learning to read, and on the other hand the dyslexia, so that they are considered two basic knowledge factors in controlling the reading process of the newly learned child, as it predicts the weakness of the working memory Phonology with dyslexia is more important than weak phonological awareness. This means that at this stage of education the phonemic working memory is entered, that is, it becomes more important to acquire reading and a relative decline in phonological awareness in order to be able to identify letter-voice harmonies. There are statistically significant differences in the mean results of the functions of phonological work memory, phonological awareness, reading tasks, and the reading deficit of the experimental group in the pre and post measurement for the benefit of post-measurement.

We also found that there was no effect of the interaction between the pedagogical training program and the sex factor (between males and females), so that the response to the program was identical between males and females. Likewise, there is no effect of an interaction between the proposed therapeutic and training program for dyslexia, the academic level and the study sample, meaning that each of the $3^{\text {rd }}$ and $4^{\text {th }}$ primary levels has the same response and positive interaction with the program activities as it is valid for all children who suffer from dyslexia at different levels of the primary stage.

Therefore, as a final conclusion here we say that the specificity of the Arabic language and the difficulty of representing its lower voices, and that we mean phonemes that differ in terms of form and pronunciation according to the position of the movements and which are also phonemes so that they are always integrated with silos or letters because it is impossible to pronounce them isolated., the skills of phonological work and phonological awareness interfere together to reach the link between letter and sound. In this study, we have noticed 
that the syllabic method is essential in teaching reading (the method of division) and the holistic or lexical method comes in later stages of learning, the researcher has a program on a book and a variety of graded activities included 100 pages. The research continues to continue in order to better control the elements of diagnosis and methods of treating reading difficulties of all kinds in the Arabic linguistic environment and address the difficulties of formal and morphological reading and the effect of the frequency and length of words and their shortness and the effect of formation and vernacular on learning to read, and learn more about the cognitive pathways interfering during the process of learning to read as well as the more brain nerve Actively.

\section{References}

Abu-Rabia, S. (1997). Reading in Arabic Orthography: The Effect of Vowels and Context on Reading Accuracy of Poor and Skilled Native Arabic Readers in Reading Paragraphs, Sentences, and Isolated Words. Journal of Psycholinguistic Research, 26(4), 465- 482.

Alegria J. et Mousty P. (2004). Les troubles phonologiques et métaphonologiques chez l'enfant dyslexique. Enfance, 56(3), 259-271.

Baccouche, T. (2003). La langue arabe : spécificités et évolution. In M. N. Romdhane, J.E.

Baddeley AD. (2003). Working memory and language: an overview. Journal of Communication Disorders, 36, 189-208.

Baddeley AD. (2007). Working Memory, Thought and Action. Oxford, UK: Oxford Univ. Press.

Barbosa, T., Miranda, M.C., Santos, R.F., \& Bueno, O.F.A. (2009). Phonological working memory, phonological awareness, and language in literacy difficulties in Brazilian children. Reading and Writing, 22, 201-218. doi: 10.1007/s11145-007-9109-3

Cohen, D. (1990). Langue arabe. In Encyclopédie Universalis, Editeur Paris ,707-732.

Coltheart, M., Rastle, K., Perry, C., Langdon, R., \& Ziegler, J. (2001). DRC: A dual route cascaded model of visual word recognition and reading aloud. Psychological Review, 108(1), 204-256.

Daneman M., Carpenter P. A. (1980). Individual differences in working memory and reading. Journal of Verbal Learning and Verbal Behavior, 19, 450-466.

De Jong P. F. (1998). Working memory deficits of reading disabled children. Journal of Experimental Child Psychology, 70, 75-96.

Demont E., Gombert J. E. (1996). Phonological awareness as a predictor of recoding skills and syntactic awareness as a predictor of comprehension skills. British Journal of Educational Psychology, 66, 315-332.

Elbro, C., \& Petersen, D. K. (2004). Long-Term Effects of Phoneme Awareness and Letter Sound Training: An Intervention Study with Children at Risk for Dyslexia. Journal of Educational Psychology, 96(4), 660-670. https://doi.org/10.1037/0022-0663.96.4.660

Ellis, N. \& Large, B. (1988). The early stages of reading: A longitudinal study. Applied Cognitive Psychology, 2, 47-76.

Frith, U. (1985). Beneath the surface of developmental dyslexia. In K. E. Patterson, J.C. Marshall \& M. Coltheart (Eds.), Surface Dyslexia: Neuropsychological and cognitive studies of phonological reading (pp. 301-330). London: Routledge \& Kegan Paul. 
Gauthier, L., Dehaut, F., \& Joanette, Y. (1989). The Bells Test: A quantitative and qualitative test for visual neglect. International Journal of Clinical Neuropsychology, 11(2), 49-54.

Habib, M., Rey, V., Daffaure, V., Camps, R., Espesser, R., Joly-Pottuz, B., \& Démonet, J. F. (2002). Phonological training in children with dyslexia using temporally modified speech: a three-step pilot investigation. International journal of language \& communication disorders, 37(3), 289-308. https://doi.org/10.1080/13682820210136278

Hutton, U.M.Z. \& Towse, J.N. (2001). Short-term memory and working memory as indices of children's cognitive skills. Memory, 9 (4/5/6), pp. 383-394.

Jacquier-Roux, M., Valdois, S., Zorman, M., Lequette, C., Pouget, G. (2005). Outil de Dépistage des Dyslexies, version 2. Grenoble: Cogni-sciences.

Ladjal, Y. (2015). The link between consciousness and phonological and work memory Phonology with phonological dyslexics in an Arabic linguistic environment and Development of a protocol Pedagogical therapy of phonological dyslexia. (Unpublished doctoral dissertation). Algers University2, Algers, Algeria.

Ladjal, Y. (2019). Learning to read and its difficulties in the Arabic linguistic environment from diagnosis to treatment. "Field Study for primary stage students". Route Educational \& Social Science Journal, 6(3), 390-412.

Lefavrais, P. (2005). L'Alouette-R. Paris : Les Editions du Centre de Psychologie Appliquée.

Mourad Ali (2007). The effectiveness of a phonological awareness training programme on reading skills of reading disabled 5-grade students. Banha Journal of Education, 17(72), 95-124.

Mousty, P., \& Leybaert, J. (1999). Evaluation des habiletés de lecture et d'orthographe au moyen de BELEC : données longitudinales auprès d'enfants francophones testés en 2ème et 4ème années. Revue Européenne de Psychologie Appliquée, 49(4), 325-342.

Nation K., Adams J. W., Bower-Crane C. A., Monk A. (1994). Working memory deficits in poor comprehenders reflect underlying language impairments. Journal of Experimental Child Psychology, 73, 139-158.

Seigneurie A., Ehrlich M. F., Oakhill J. V., Yuill, N. M. (2000). Working memory resources and children's reading comprehension. Reading and Writing: An Interdisciplinary Journal, $13,81-103$.

Siegel, L.S. \& Ryan, E.B. (1988). Development of grammatical sensitivity, phonological and shorter memory skills in normally achieving and learning-disabled children. Developmental Psychology, 24, 28-37.

Sprenger-Charolles L., Colé P., Béchennec D., \& Kipffer-Piquard A. (2005). French normative data on reading and related skills: From 7 to 10 year-olds. European Review of Applied Psychology/Revue Européenne de Psychologie Appliquée, 55, 157-186.

Swanson H. Lee, 1999. Reading Research for Students with LD: A Meta-Analysis of Intervention Outcomes. Journal of Learning Disabilities, 32(6), 504-532.

Swanson H. Lee, 2000. Issues Facing the Field of Learning Disabilities. Learning Disability Quarterly,23(1), 37-50.

Swanson, H. L., \& Howell, M. (2001). Working memory, short-term memory, and speech rate as predictors of children's reading performance at different ages. Journal of Educational Psychology, 93(4), 720-734. https://doi.org/10.1037/0022-0663.93.4.720 
Treiman, R., Freyd, J. J., \& Baron, J. (1983). Phonological recoding and use of spellingsound rules in reading of sentences. Journal of Verbal Learning \& Verbal Behavior, 22(6), 682-700. https://doi.org/10.1016/S0022-5371(83)90405-X

Wagner, R. K., Torgesen, J. K., Rashotte, C. A., Hecht, S. A., Barker, T. A., Burgess, S. R. et al. (1997). Changing relations between phonological processing abilities and word-level reading as children develop from beginning to skilled readers: A 5-year longitudinal study. Developmental Psychology, 33, 468-479. http://dx.doi.org/10.1037/0012-1649.33.3.468

Wagner, R.K. \& Muse, A. (2006). Short-term memory in developmental dyslexia. In T.P. Alloway \& S.E. Gathercole (Eds.). Working Memory and Neurodevelopmental Disorders, 41-57.

Wolf, M., Bowers, P. G., \& Biddle, K. (2000). Naming-speed processes, timing, and reading : a conceptual review. Journal of Learning Disabilities, 33(4), 387-407. https://doi.org/10.1177/002221940003300409

Ziegler, Johannes-C., Goswami, U. (2005). Reading Acquisition, Developmental Dyslexia, and Skilled Reading Across Languages: A Psycholinguistic Grain Size Theory. Psychological Bulletin, 131(1), 3-2. 